\title{
Saturation and hysteresis effects in ionospheric modification experiments observed by the CUTLASS and EISCAT radars
}

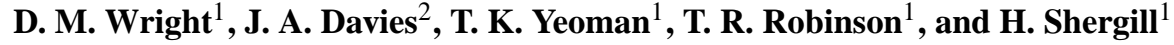 \\ ${ }^{1}$ Department of Physics and Astronomy, University of Leicester, University Road, Leicester LE1 7RH, UK \\ ${ }^{2}$ Space Science and Technology Department, Rutherford Appleton Laboratory, Chilton, Didcot, Oxon, OX11 0QX, UK
}

Received: 4 February 2005 - Revised: 25 October 2005 - Accepted: 16 January 2005 - Published: 23 March 2006

\begin{abstract}
The results of high latitude ionospheric modification experiments utilising the EISCAT heating facility at Troms $\varnothing$ are presented. As a result of the interaction between the high power pump waves and upper hybrid waves in the ionosphere, field-aligned electron density irregularities are artificially excited. Observations of these structures with the CUTLASS coherent HF radars and the EISCAT incoherent UHF radar exhibit hysteresis effects as the heater output power is varied. These are explained in terms of the two-stage mechanism which leads to the growth of the irregularities. Experiments which involve preconditioning of the ionosphere also indicate that hysteresis could be exploited to maximise the intensity of the field-aligned irregularities, especially where the available heater power is limited.

In addition, the saturation of the irregularity amplitude is considered. Although, the rate of irregularity growth becomes less rapid at high heater powers it does not seem to fully saturate, indicating that the amplification would continue beyond the capabilities of the Troms $\emptyset$ heater - currently the most powerful of its kind. It is shown that the CUTLASS radars are sensitive to irregularities produced by very low heater powers (effective radiated powers $<4 \mathrm{MW}$ ). This fact is discussed from the perspective of a new heating facility, SPEAR, located on Spitzbergen and capable of transmitting high frequency radio waves with an effective radiated power $\sim 10 \%$ of that of the Troms $\varnothing$ heater (28 MW).
\end{abstract}

Keywords. Ionosphere (Active experiments; Ionospheric irregularities) - Radio science (Ionospheric physics)

\section{Introduction}

Artificial ionospheric modification was first discovered in the 1930s when large broadcasting stations started transmitting high power radio signals. The effect was first noted when the modulation of Radio Luxembourg could be heard in the

Correspondence to: D. M. Wright

(darren.wright@ion.le.ac.uk) background of other radio signals which passed through the region of the ionosphere illuminated by its beam. The Luxembourg effect, as it was first called, was later explained as cross-modulation between the two radio signals caused by the high-power transmission modifying the radio propagation characteristics of the ionosphere for the other radio path (Tellegen, 1933; Bailey and Martyn, 1934). However, the first purpose-built radio frequency (RF) ionospheric "heaters" were not constructed until the early 1970s. These were then employed to perform experiments in the natural plasma laboratory provided by the ionospheric medium.

The first reported ionospheric modification (heating) experiments, performed at Platteville, Colorado, revealed that the transmission of a high power pump wave led to the generation of field-aligned electron density irregularities (FAIs; Fialer, 1974; Minkoff et al., 1974). These occur as a result of coupling between the electromagnetic heater wave and upper hybrid waves at the upper hybrid resonance height. Since $\mathrm{X}$-mode polarised radio waves reflect below this height, the irregularities are only generated by $\mathrm{O}$-mode radiation. These structures can then act as intense targets for HF coherent scatter radars (Robinson et al., 1997). Detailed discussions of these heater-induced phenomena are given in the reviews by Robinson (1989) and Stubbe (1996). In the F-region, it is the anomalous self absorption of the O-mode heater wave at the upper hybrid altitude that gives rise to the enhancement in the electron temperature that gives it name to heating. Throughout the region of electron temperature enhancement the electron density mainly increases due to the temperature dependence of the recombination, although on a longer time-scale than that exhibited by the electron temperature.

A number of theories relating to the stimulation of artificial FAIs by a high power pump beam have been put forward over the years. One invokes the thermal oscillating twostream instability (TOTSI; e.g. Dysthe et al., 1983) for the creation and rapid growth of the FAIs. More recently, Gurevich et al. (1995) constructed a stationary theory of striation formation based on resonance instability. The TOTSI most readily explains the radar observations which are presented

Published by Copernicus GmbH on behalf of the European Geosciences Union. 


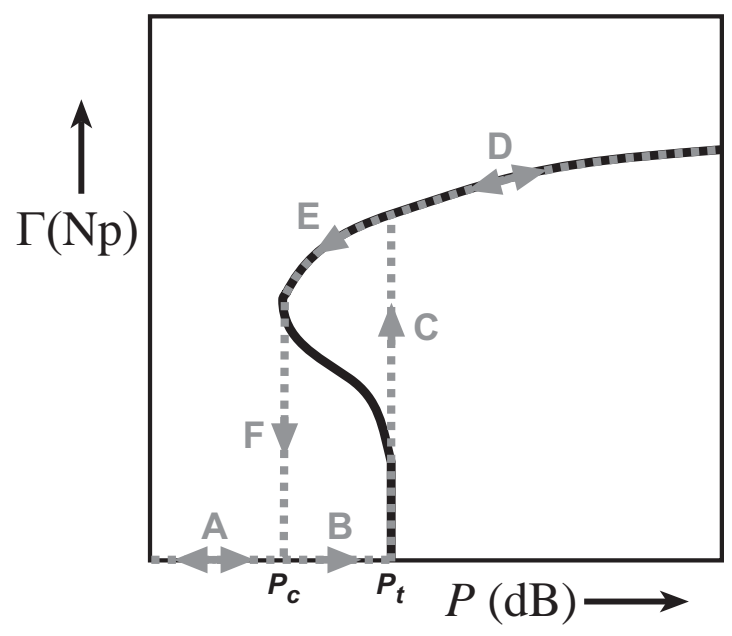

Fig. 1. A theoretical curve showing the relationship between anomalous absorption and heater power (solid curve). The dashed lines show the different paths that lead to the hysteresis effect.

in this study. In addition, a drawback of the theory of Gurevich et al. (1995) is that it predicts abnormally high increases in electron temperature caused by the heater despite a relatively small electron density perturbation (Borisov et al., 2005). These large enhancements in electron temperature have not so far been detected.

Initially, the TOTSI causes a linear conversion of electromagnetic pump wave energy into upper hybrid waves (Vaskov and Gurevich, 1977; Dysthe et al., 1983; Robinson, 1988). This coupling requires the presence of plasma density gradients (pre-existing FAIs) and leads to an increase in the FAI amplitude. Once this amplitude exceeds a threshold value (typically after a few milliseconds) the interaction becomes nonlinear and the irregularity amplitude increases explosively. One hypothesis suggests that it is the anomalous absorption of the pump itself (i.e. the conversion of the electromagnetic pump wave into high frequency electrostatic waves at the upper hybrid height) as a result of the interaction with the heater-induced irregularities, that ultimately limits the growth of the FAIs (e.g. Robinson, 2002). Under these circumstances, the relationship between the pump power, $P$, and the level of anomalous absorption, $\Gamma \mathrm{s}$ is given by

$$
P\left[e^{-\Gamma / 2} \frac{1-(\cosh (\Gamma / 2)-1)(\ln a) / \pi}{P_{1}}+\frac{\Gamma e^{\left(\Gamma_{0}-\Gamma\right) / 4}}{\Gamma_{0} P_{2}}\right]=1
$$

where $P_{1}$ and $P_{2}$, respectively, are the required power thresholds for the initial and explosive stages of FAI growth, $\Gamma_{0}$ is the level of anomalous absorption before the heater was activated and $a$ is a factor relating to the field parallel scale length of the FAIs (see Robinson, 1989). The two terms in Eq. (1) represent the initial and explosive instabilities. Since anomalous absorption $\Gamma \propto n^{2}$, where $n$ is the FAI amplitude, then irregularity saturation as governed by Eq. (1) is shown as the solid curve in Fig. 1 in which $\Gamma$ is plotted as a function of $P$.

Grach et al. (1978) first postulated that a thermal parametric instability such as the TOTSI should be expected to exhibit hysteresis effects. The existence of hysteresis was confirmed by the ionospheric modification experiments reported by Erukimov et al. (1978) and subsequently by Stubbe et al. (1982) and Jones et al. (1983). A hysteresis effect occurs in the generation of FAI because the threshold power, $P_{t}$, (shown in Fig. 1) required for the onset of FAI growth is higher than the critical pump power, $P_{c}$, at which the FAI can no longer be sustained and, hence, collapse. The effective threshold power is given by

$P_{t}=\frac{P_{1} P_{2}}{P_{1}+P_{2}}$

where $P_{t}$ is larger than both $P_{1}$ and $P_{2}$. So, once the heater power $P>P_{t}$ then the FAI form explosively and saturation is rapid. This is demonstrated in Fig. 1 by the path ABCD. If the pump power is then steadily reduced, the FAI do not collapse until $P<P_{c}$, therefore following path DEFA.

This paper will mainly focus on observations of hysteresis effects caused by ionospheric modification experiments using the EISCAT Heater at Troms $\emptyset$ during a campaign in 1997, and diagnosed by the CUTLASS high frequency (HF) coherent radars and the EISCAT UHF incoherent scatter radar at Troms $\varnothing$. The hysteresis effects are known to be related to the generation of FAIs since they do not occur when X-mode polarised heater waves are transmitted which, as noted previously, are not associated with irregularity generation. The CUTLASS data presented here represent direct measurements of the FAI amplitude and are significant for defining the irregularity power thresholds and saturation levels associated with backscatter received by the CUTLASS radar. They have provided a way of estimating the expected performance of the new SPEAR (Space Plasma Exploration by Active Radar; Wright et al., 2000) high power heating facility which has just been deployed at the high latitude location of Spitzbergen in the Svalbard archipelago.

\section{Instrumentation}

\subsection{The EISCAT high power heating facility}

The high power HF heating facility located near Troms $\varnothing$ transmits up to $1 \mathrm{MW}$ of power which is radiated through one of three $6 \times 6$ phased arrays of rhombically broadened crossed dipole antennas. Different radiated frequencies, within the range 4 to $8 \mathrm{MHz}$, can be achieved by selection of arrays 2 or 3, providing an effective radiated power of 276 MW (M. Rietveld, private communication). However, all of the data presented in this paper were taken with the heater operating in O-mode at a frequency of $4.544 \mathrm{MHz}$ with its beam pointing along the field line. During the experiments in October 1997, specially designed modes permitted 


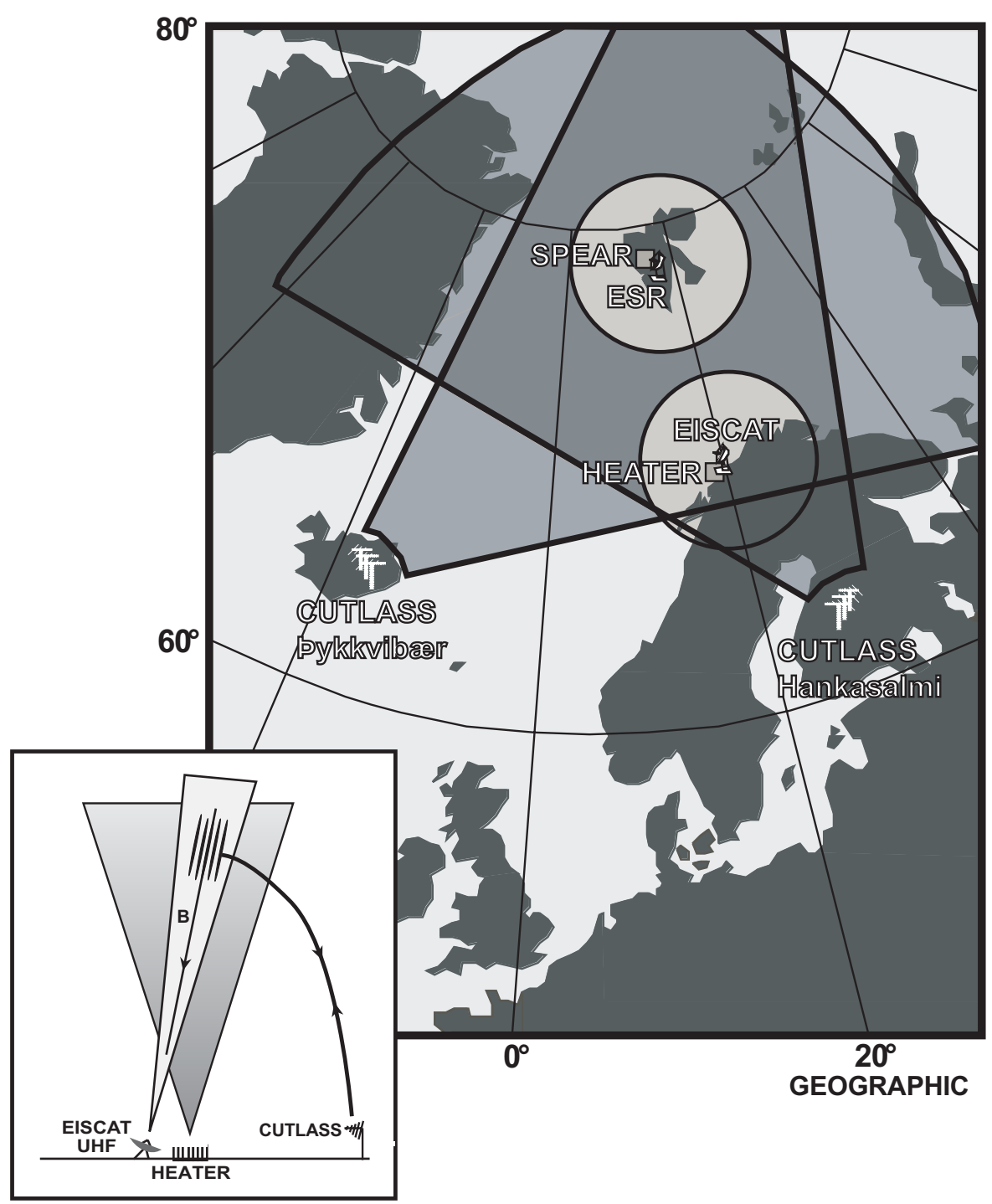

Fig. 2. A map illustrating the locations of the various instruments relevant to this study. Inset: a schematic representation of field-aligned irregularity generation by a high power heater and a half-hop radio path of an HF radar which receives backscatter from these structures.

the slow variation of the heater's output power in order to test power thresholds, irregularity saturation and ionospheric preconditioning. The maximum effective radiated power (ERP) on these occasions was $155 \mathrm{MW}$ (using 10 out of an available 12 transmitters) radiated with a full width at half maximum beam width of $15^{\circ}$. Further technical information on the EISCAT high power HF heating facility can be found in Rietveld et al. (1993).

\subsection{The CUTLASS radars}

The global SuperDARN radar network (Greenwald et al., 1995) currently consists of $15 \mathrm{HF}$ coherent radars, 9 of which operate in the Northern Hemisphere. Two of the Northern Hemisphere SuperDARN radars comprise the CUTLASS (Co-operative UK Twin Located Auroral Sounding System) system. CUTLASS is a frequency agile bistatic HF radar system (e.g. Milan et al., 1997) operating in the range 8$20 \mathrm{MHz}$ and consisting of stations at Pykkvibær, Iceland and Hankasalmi, Finland. Figure 2 shows the fields of view of these radars, whilst operating in their standard mode, on a ground projection along with the locations of the facilities at Troms $\varnothing$ and on Spitzbergen. The signals returned to the radars have undergone a Bragg-like backscattering process from FAIs in the ionosphere. There is an aspect angle dependence for scattering, which requires that the radio wave $\boldsymbol{k}$ vector is close to orthogonal to the magnetic field. The experiments described here utilise the EISCAT high power HF Heating facility at Troms $\varnothing$ which can generate artificial field-aligned irregularities as described earlier and thus provide a region of backscatter in the CUTLASS fields of view 


\section{SUPERDARN PARAMETER PLOT}

\section{Hankasalmi and Pykkvibær (pwr_I) 6 Oct 1997}

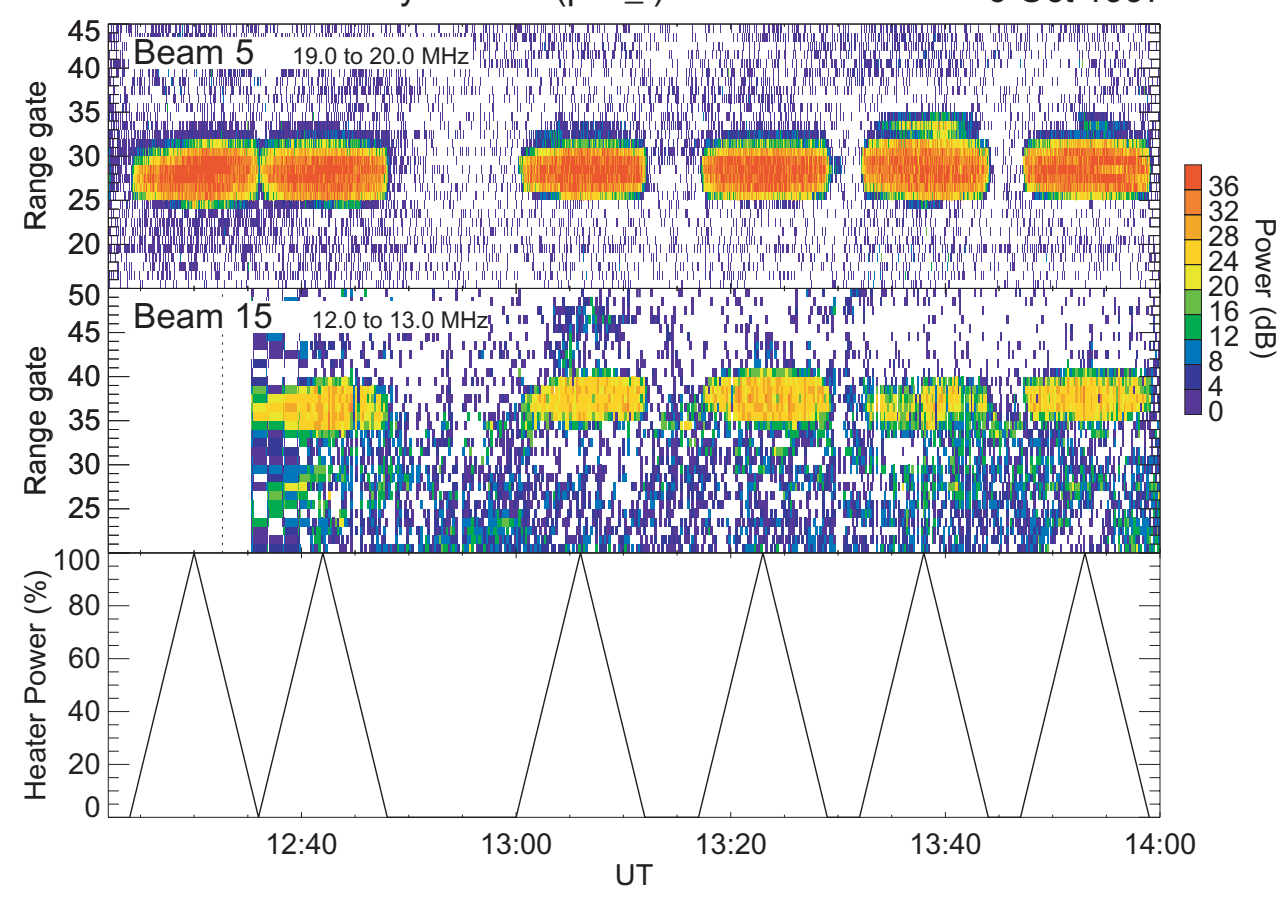

Fig. 3. Backscatter power (pwr_l) measurements from the CUTLASS Hankasalmi (upper panel) and Pykkvibær (middle) radars during the power stepping experiment utilising the Troms $\varnothing$ heater on 6 October 1997. The lower panel shows the output heater power as a function of time during these observations.

(e.g. Robinson et al., 1997) when backscatter may not already be present. This effect is illustrated schematically as the inset in Fig. 2. The detection of artificial backscatter by HF radar then provides a powerful way of diagnosing plasma processes (e.g. Robinson et al., 1997) and observing geophysical phenomena (e.g. Yeoman et al., 1997).

During the experiments relevant to this paper, the CUTLASS radars employed a range resolution of $15 \mathrm{~km}$, compared to a normal gate length of $45 \mathrm{~km}$. The radars were, as a result, sounding over a reduced field of view compared with that shown in Fig. 2, centred over Troms $\varnothing$ during these experiments. The nearest range sounded on the Hankasalmi and Pykkvibær radars were, respectively, $480 \mathrm{~km}$ and $1470 \mathrm{~km}$. Troms $\varnothing$ lies at approximately $900 \mathrm{~km}$ from the Hankasalmi radar and is twice as remote from Pykkvibær. Typically, the time resolution of the radar data presented varies from 1$10 \mathrm{~s}$. Only data from beam 5 of the Hankasalmi radar and beam 15 of Pykkvibær have been employed as these beams overlie Troms $\varnothing$, the location of the EISCAT heater. The high backscatter powers that are characteristic of artificially generated irregularities make it possible to integrate data over such short dwell times since the signal to noise levels are high.

\subsection{The EISCAT UHF radar}

The European Incoherent Scatter (EISCAT) UHF radar (e.g. Rishbeth and Williams, 1985; Rishbeth and van Eyken, 1993) is often operated in support of artificial modification experiments using the Troms $\varnothing$ heater (see Sect. 2.1). The SP-UK-HEAT experiments in October 1997, included UHF radar operation, with the transmit/receive antenna at Ramfjordmoen near Troms $\varnothing$, Norway, aligned approximately along the local magnetic field direction (geographic azimuth: $183.2^{\circ}$, elevation: $77.2^{\circ}$ ). Four pulse schemes were transmitted; long pulse, alternating code and two power profiles; only data from the former is included here. The long pulse scheme provides observations of electron density, ion and electron temperature and line-of-sight ion velocity over 21 range gates along the Troms $\emptyset$ beam, from approximately 140 to $600 \mathrm{~km}$ altitude with a gate separation of $\sim 22 \mathrm{~km}$ in altitude.

\section{Observations}

\subsection{Radar observations of hysteresis}

On 6 October 1997 an experiment was undertaken where the heater output power was, for a number of cycles, increased 
from $0 \%$ to $100 \%$ output, using $2.5 \%$ steps and then decreasing the power again to $0 \%$ in the same fashion. Each step was maintained for $9 \mathrm{~s}$ so that the entire cycle took exactly 12 min to complete. The upper and middle panels of Fig. 3 show colour-coded range-time-intensity plots of backscatter power from the Hankasalmi and Pykkvibær radars, respectively, with observations from both HF radars revealing the artificial irregularities generated by the heater over the course of the experiment. The data shown in Fig. 3 were measured at a sounding frequency in the range $19.0-20.0 \mathrm{MHz}$ and a time resolution of $1-2 \mathrm{~s}$ for the Hankasalmi radar (top panel), whilst Pykkvibær (middle panel) transmitted in the range $12.0-13.0 \mathrm{MHz}$ with a time resolution of $10 \mathrm{~s}$. The lower panel shows the heater output power over the same interval. Five of the total of six full cycles were preceded by extended periods during which the heater was off to remove the possibility of any ionospheric preconditioning (see Sect. 3.2) being caused by the heater. The Pykkvibær radar was not switched into its high time resolution mode until half way through the second cycle. The intense backscatter from Hankasalmi was centred on range gate 28 (900 km distant) and that from Pykkvibær was centred on range $37(2025 \mathrm{~km}$ from the radar). The latter observations exhibit a range ambiguity from the expected $\sim 1800 \mathrm{~km}$ ground range. This is related to the fact that the range calculation algorithm is less accurate over the 1.5 hop ray path geometry required for Pykkvibær to observe scatter over Troms $\emptyset$. In contrast, Hankasalmi acquires scatter over Tromsø over a 0.5 hop path. These observations are commensurate with the findings of Yeoman et al. (2001), who employed artificial backscatter to make a range evaluation for the CUTLASS radars. The extra distance travelled by the Pykkvibær radar signal accounts for the lower backscatter power received by this radar, which are roughly $10-20 \mathrm{~dB}$ down on those received by the Hankasalmi radar.

Figure 4 presents the Hankasalmi HF radar data from the first cycle only, from 12.24 to 12.36 UT. Panel (a) shows the time series data of backscatter power from range 28 of beam 5, which is in the middle of the patch of artificial scatter. Panel (b) illustrates the power stepping heater cycle at the same time. By plotting the radar backscatter power as a function of heater output for the increasing and decreasing parts of the power cycle (Fig. 4c) a difference in the received radar power is immediately apparent. During the powerincreasing part of the heater cycle the backscatter power increases rapidly until the heater output reaches $20 \%$ and thereafter continues to increase more steadily approaching a saturation level of about $40 \mathrm{~dB}$. On the way back down the twostage backscatter power fall-off is less rapid than the equivalent steps on the way up to maximum heater output. The result of this is that right down to the lowest power transmitted by the heater $(2.5 \%$, equivalent to an ERP of only $3.9 \mathrm{MW}$ ) the difference in backscatter power caused by the hysteresis, $\Delta P_{d-u}$, is $\sim 20 \mathrm{~dB}$. Figure 5 shows the equivalent plots to Fig. $4 \mathrm{c}$ for all six cycles in the experiment. A
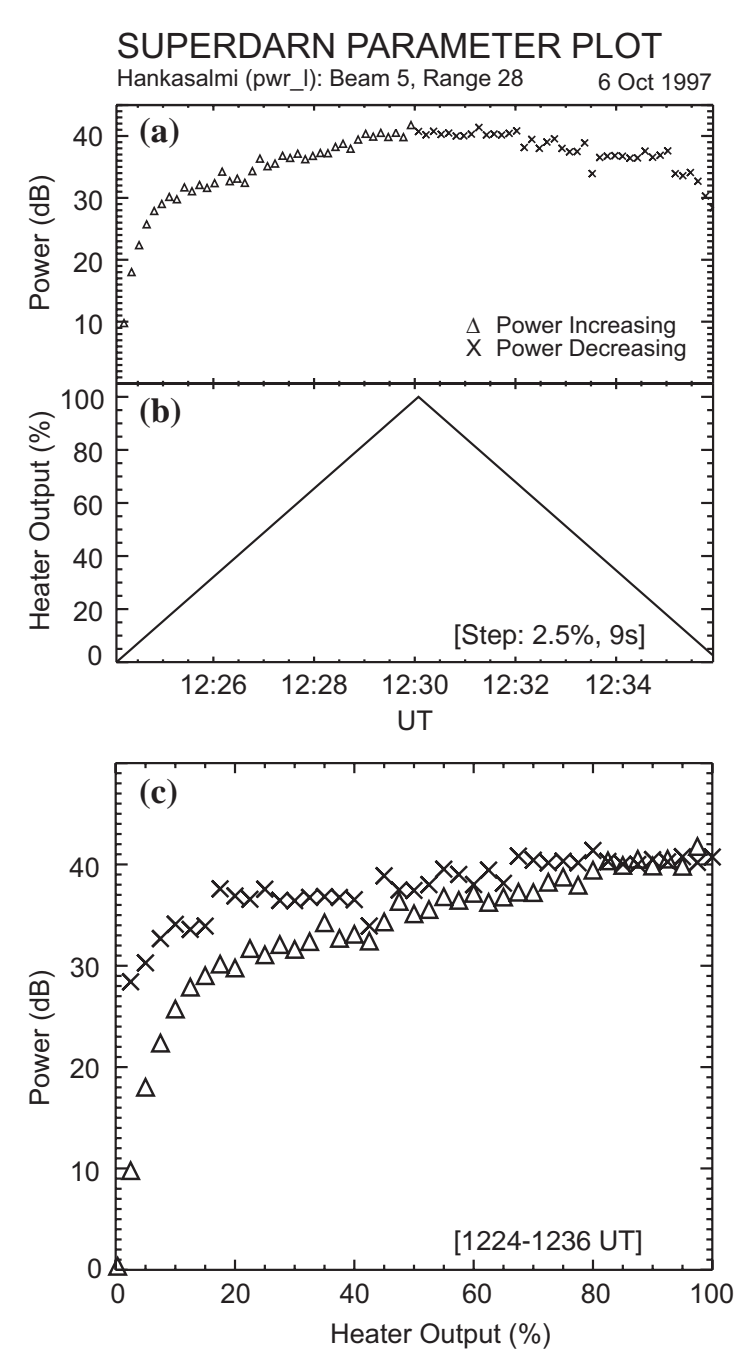

Fig. 4. (a) The received backscatter power from range 28 of beam 5 of the Hankasalmi radar during one cycle of the power stepping experiment shown in Fig. 3. (b) The power output of the heater during this cycle. Panel (c) shows the measurements in (a) as a function of the heater output (b) with the two halves of the cycle plotted separately to indicate the level of hysteresis between the upand down-going parts of the cycle.

similar hysteresis signature can be seen in all panels a-f although there appears to be less distinction between the upand down-going parts of the cycle at heater powers greater than $20 \%$ in panels (b-f). The smallest separation $\Delta P_{d-u}$ at low heater powers is observed to occur for the second cycle (Fig. 5b). However, it is likely that since there was no recovery time (i.e. and extended heater off interval) following the first cycle then the second cycle was affected by ionospheric preconditioning. This will be discussed later.

Simultaneous field-aligned EISCAT UHF measurements of the electron temperature $\left(T_{e}\right)$ and density $\left(N_{e}\right)$ in the modified ionosphere are illustrated in Fig. 6 as a function of altitude for the UT period that covers all 6 heater cycles. Large 


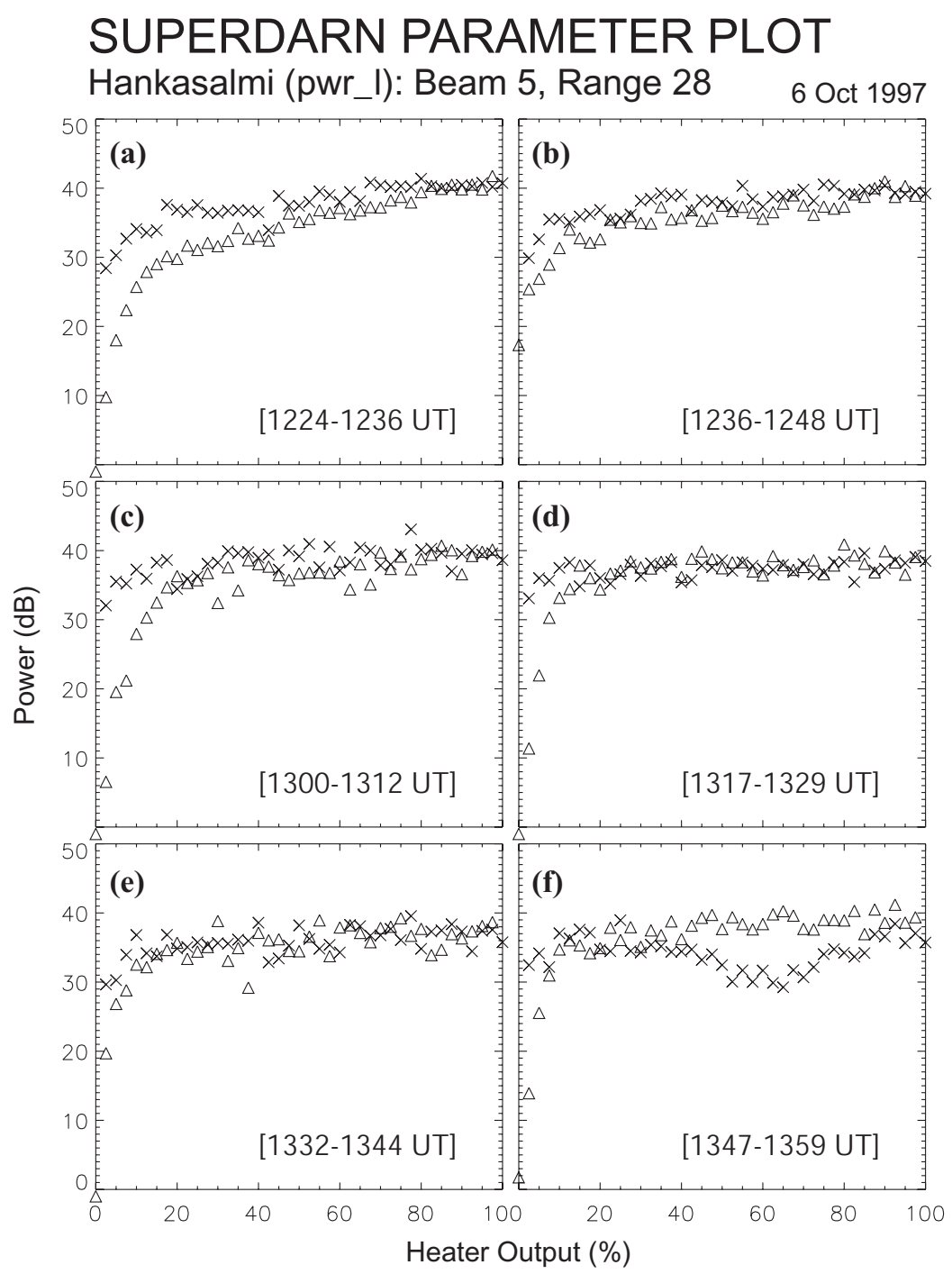

Fig. 5. As for Fig. 4c but for all six cycles (a-f) shown in Fig. 3.

enhancements of the electron temperature correspond to the intervals when the heater was operating and, moreover, the temperature can be seen to increase with the Heater power and lead to changes in the electron temperature $\Delta T_{e} / T_{e}$ of $\sim 100 \%$ at maximum heater output. The interaction altitude, where the pump wave couples to upper hybrid waves, was derived from the location of "overshoot" effects observed in the ion line measurements made by the UHF radar and was found to vary from $180-200 \mathrm{~km}$ for this interval. There is, as has been demonstrated by Jones et al. (1986) and Robinson (1989), a linear relationship between the electron temperature enhancement $\Delta T_{e}$ of the modified ionosphere and the level of anomalous absorption, $\Gamma$, and hence irregularity amplitude. Figure 7 shows the variation of $\Delta T_{e}$ (normalised with respect to the heater output power) as a function of heater output for the first cycle in our interval. It should be noted that the response time for changes in $T_{e}$ is of the same order as the time between steps in the Heater power cycles (Stocker et al., 1992) and as a result a slight time offset in the overall response throughout the heater cycle is expected to exist. However, again a hysteresis effect is clearly seen where the electron temperature corresponding to the final steps in the heater cycle is far higher than the value of the temperature during the initial heater steps. There is also some evidence to suggest that hysteresis is exhibited by the electron densities (not shown) where the maximum value of $\Delta N_{e} / N_{e}$ was $\sim 10 \%$. However, these relatively small changes are masked by large changes in the ambient electron density. The electron temperatures on the up-and downgoing parts of the heater cycle only differ significantly for heater powers below $30-40 \%$ where CUTLASS backscatter power and irregularity amplitude are changing the fastest. 


\section{EISCAT UHF Radar}

6 October 1997

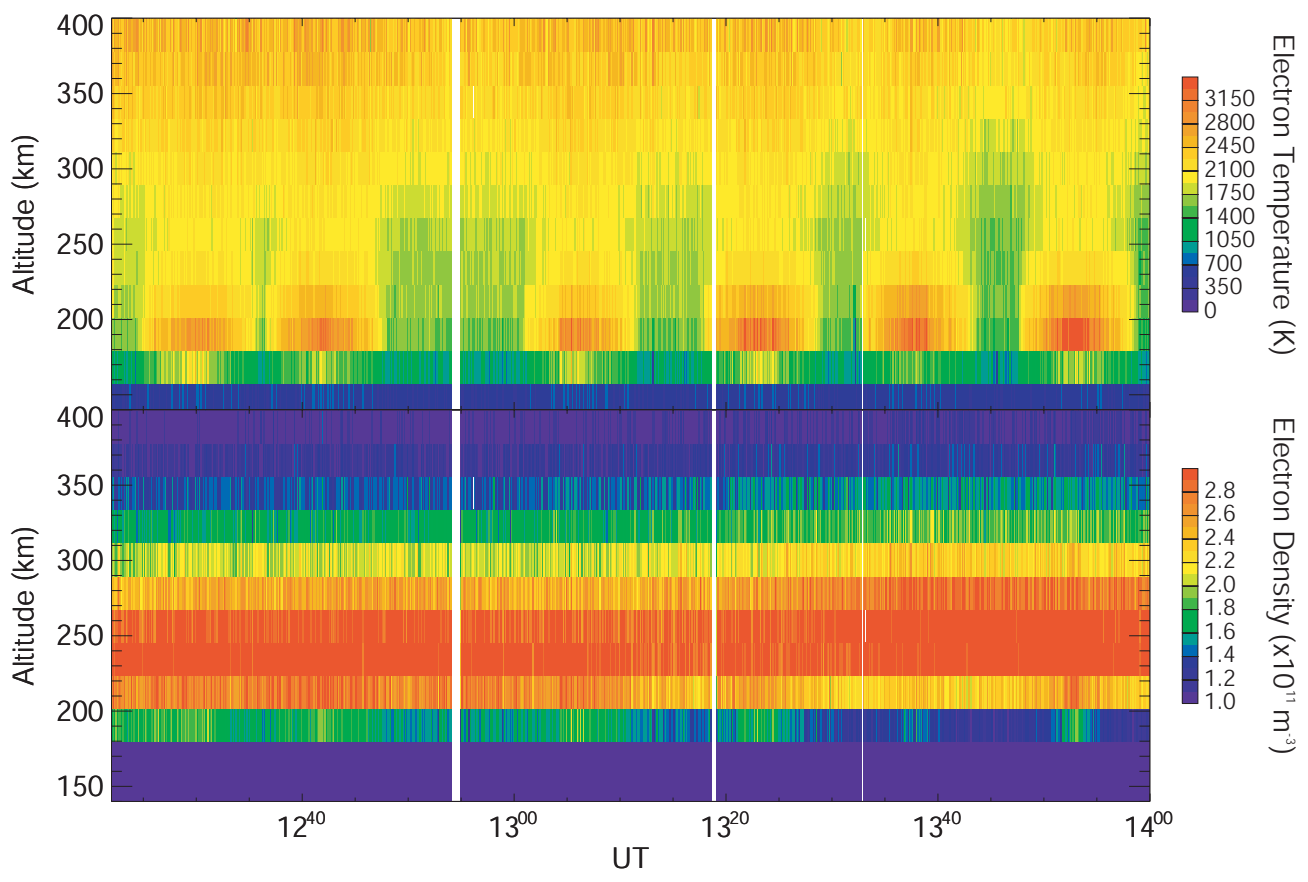

Fig. 6. Ionospheric electron temperature (upper panel) and electron density (lower panel) measured by the EISCAT UHF radar whilst pointing field aligned during the interval shown in Fig. 3.

\subsection{Ionospheric preconditioning}

Once the ionosphere has been modified it may remain in this state for some time after the heater has been turned off. This is most clearly apparent on occasions when the artificial FAI take several minutes to decay. In order for unbiased heating effects to be observed it is often necessary to leave long off periods (several minutes) between intervals of heater on to give the ionosphere time to return to its unmodified state. Changing the ionospheric conditions prior to another type of experiment is known as preconditioning. A study of CUTLASS backscatter from heater-generated irregularities by Bond (1997) demonstrated that the decay time of FAI (and hence the duration of this preconditioning) was dependent on the time of day and was observed to vary from $\sim 50$ in the early afternoon to $\sim 200 \mathrm{~s}$ towards dusk.

On 7 October 1997, an experiment was performed to investigate the effects of irregularity saturation, by heating the ionosphere at low power levels, and preconditioning by using relatively short-lived high power pulses prior to longer but low power heater cycles. The backscatter power received by the CUTLASS Hankasalmi radar during this experiment is reproduced in the middle panel of figure 8 , in which a series of patches of artificial backscatter can be seen. The upper panel of the figure shows a time series of the backscatter power at range gate 30 , located at the centre of the heated

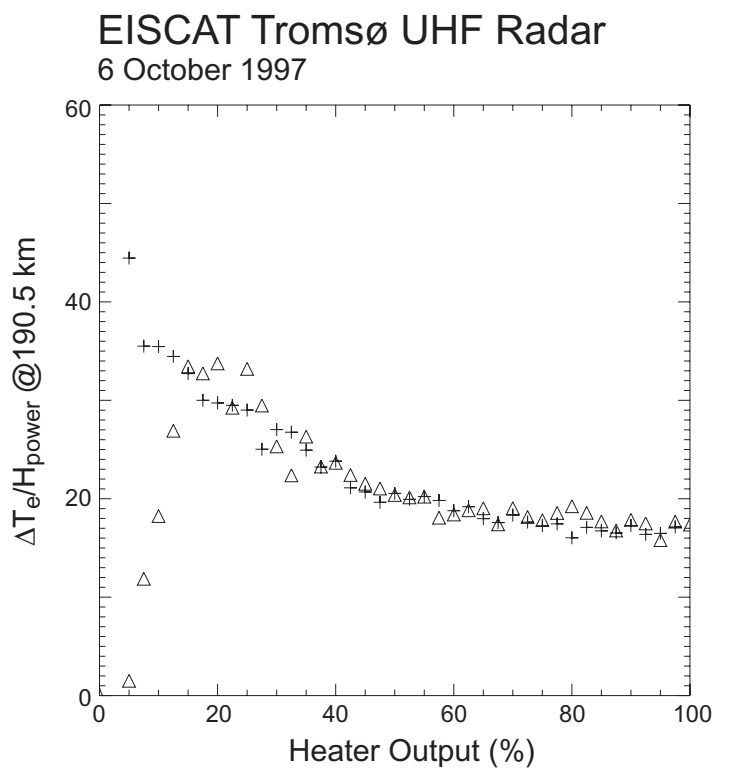

Fig. 7. The temperature change of the electrons in the modified ionosphere normalised by and plotted as a function of the heater output power. Again the up- and down-going parts (respectively symbolised by $\Delta$ and + ) of the same heater cycle as in Fig. 4 are overlaid to illustrate the hysteresis effect. 


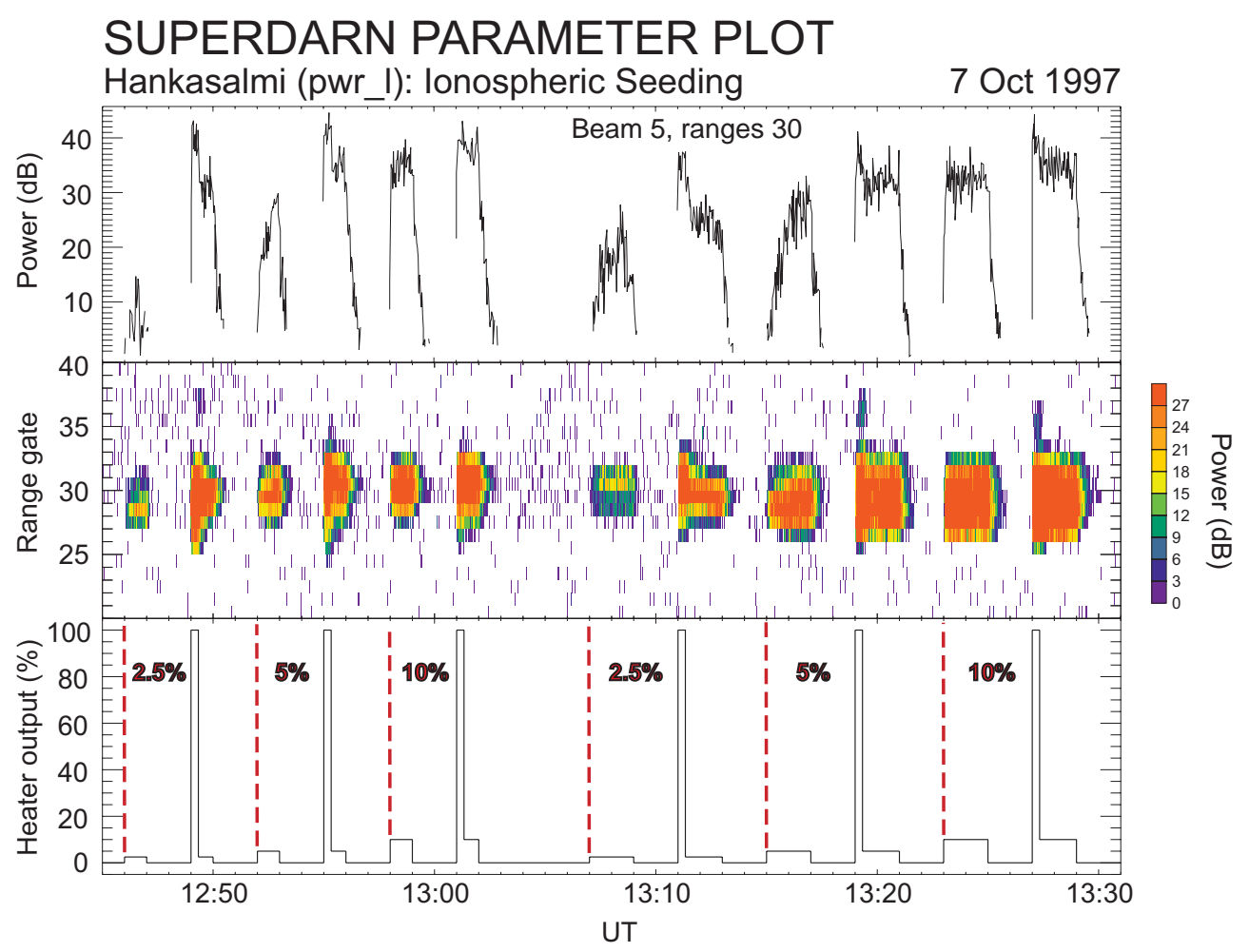

Fig. 8. The results of the ionospheric seeding experiment of 7 October 1997: The middle panel shows the backscatter power received by the Hankasalmi radar along beam 5 during heating with the Troms $\varnothing$ facility. Plotted in the upper panel is the backscatter power at range gate 30 along this beam. The lower panel depicts the heater output power throughout this interval.

patch. Indicated in the lower panel is the heater power. From 12:46 to 13:04 UT the underlying cycle was 1 min of heater on followed by 2 min of heater off. These cycles were arranged in pairs with each transmitting the same final output power. However, for the first $20 \mathrm{~s}$ of the second cycle in each pair the heater transmitted at full power. This shall hereafter be termed the "seed pulse". The final output power in each of the three pairs was, in turn, $2.5 \%, 5 \%$ and $10 \%$ of full power, as is evident in Fig. 8. The whole process was subsequently repeated from 13:07 to 13:31 UT but now using an underlying $2 \mathrm{~min}$ on, $2 \mathrm{~min}$ off heater cycle (see Fig. 8). It is evident from the upper panel of Fig. 8 that the backscatter power observed by the Hankasalmi radar was considerably higher in those cycles with an initial seed pulse. Furthermore, in the absence of the seed pulse a larger backscatter power was received during a 2-min heater on than for a 1min heater on. This implies that at heater powers below $10 \%$ irregularity saturation required longer than $60 \mathrm{~s}$ in each case. The increase in backscatter power, $\Delta P_{\text {seed }}$, obtained by the use of the seed pulse, compared to that without, is indicated in Fig. 9. The upper panel of the figure corresponds to the 1-min on-1-min off cycles and the lower panel, to the 2-min on-2-min off cycles. For each pair of cycles corresponding to each final heater power (i.e. 2.5, 5 and 10\%), the average backscatter power from Hankasalmi is plotted as a cross for the cycle containing a seed pulse and a plus sign for the cycle without. At low heater powers such as those employed in this experiment $(0-10 \%)$ the effects of using the seed pulse (ionospheric preconditioning) are dramatic and the duration that the heater is active is also significant for the saturation of irregularities created by the heater. $\Delta P_{\text {seed }}$ was as large as $25 \mathrm{~dB}$ when using a seed pulse followed by the short duration heating interval at $2.5 \%$ output.

\section{Discussion and conclusion}

This paper has presented the results of ionospheric modification experiments on two consecutive days in October 1997 employing the high power heating facility at Troms $\varnothing$. The CUTLASS HF coherent radars received backscatter from irregularities artificially generated by the heater. These irregularities provide a very coherent and intense target for the radars facilitating high spatial and temporal resolution diagnosis of the plasma physical processes that lead to their existence.

These experiments provide important insight into the growth and saturation of artificially stimulated FAI. A clear hysteresis effect is observed between the up- and down-going parts of the heater cycle, the difference in radar backscatter 


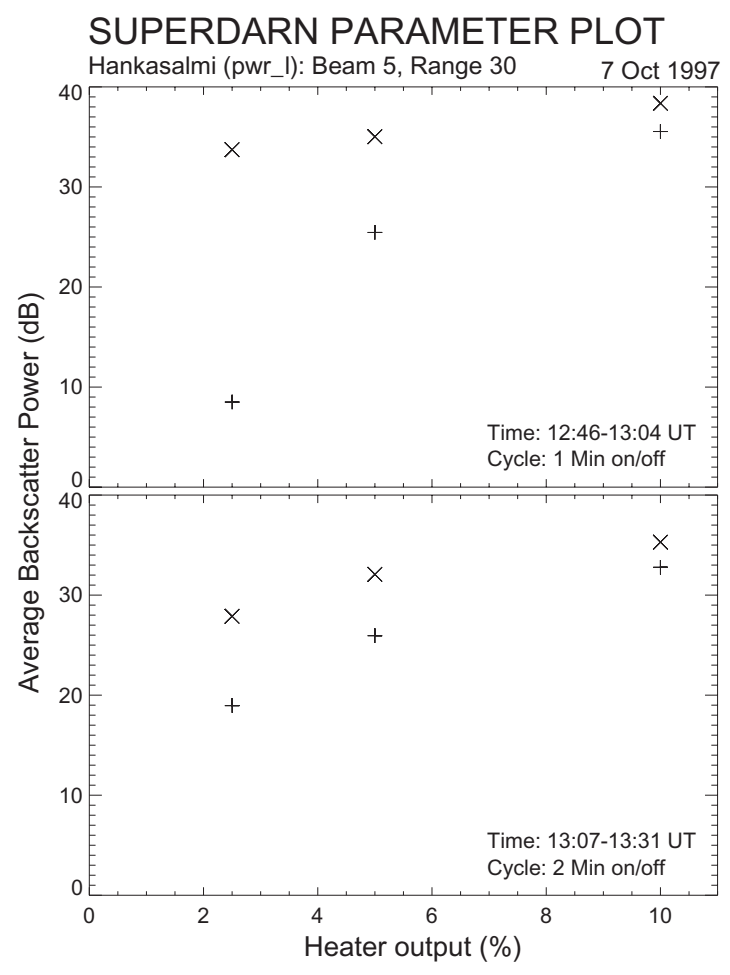

Fig. 9. The difference in average backscatter power received by the Hankasalmi radar as a function of heater output when the ionosphere is $(\mathrm{x})$ and is not $(+)$ pre-conditioned by a preceding high power pulse from the heater. The upper (lower) panel shows data from 1 (2)-min on, 1 (2)-min off heater cycles.

powers being most marked at low heater powers, where $\Delta P_{d-u}$ is typically $20 \mathrm{~dB}$ (or 100 times) more intense on the down-leg. This is consistent with the theoretical curve shown in Fig. 1. As expected a similar effect is also observed in the EISCAT measurements of electron temperature, which is modified by the heater interaction with the ionospheric plasma. Since the electron temperature is known to be proportional to the level of anomalous absorption (and hence related to irregularity amplitude) then the curve in Fig. 1 should also be applicable to the EISCAT observations. The growth of the irregularities indicated by the CUTLASS measurements (see Fig. 4) occurs in two stages. For heater powers less than $\sim 20 \%$ there is a very rapid increase in backscatter power and as the heater power is increased further the irregularity amplitude grows more steadily looking as though it is approaching a saturation value. However, in the observations presented here, the CUTLASS backscatter power never appears to quite saturate fully and presumably would continue to rise if the heater power could be increased further. It has been hypothesised that the extinction (self absorption) of the heater itself by interaction with its own FAI would limit the amplitude of the FAI, and therefore the backscatter powers observed by the radars.

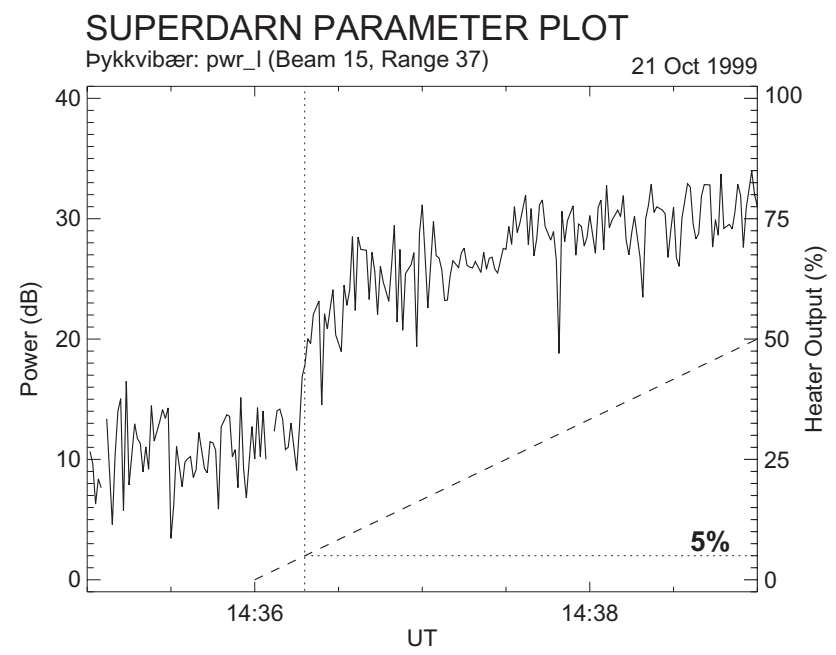

Fig. 10. Backscatter power received from the heated volume by the Pykkvibær radar (beam 5, range 37) during the up-going part of a similar heater cycle to that shown in Fig. 4. The dashed line shows the heater output power during this interval, given by the scale on the right hand side of the plot.

The hysteresis effects observed are the result of a form of preconditioning. This is borne out by the ionospheric seeding experiments, the results of which are shown in Figs. 8 and 9. Again, it is consistently observed that after a short high-power pulse much higher backscatter powers can be achieved for a given heater output level. This is particularly pronounced for low heater powers where the backscatter observed is as much as $20 \mathrm{~dB}$ more intense than for simply transmitting heater radiation at low powers. This indicates that, although a power threshold, $P_{t}$, has to be exceeded for FAI growth to occur (see Fig.1), once the irregularities exist they can be maintained with much lower heater powers, as long as this remains greater than $P_{c}$. This might be important where available heater power is limited.

One important motivation for these experiments was to evaluate the expected performance of the new heating facility, SPEAR, which is located almost $10^{\circ}$ further north than Troms $\varnothing$ in Svalbard $\left(78^{\circ} \mathrm{N}\right.$ geographic). Currently, the maximum power output of SPEAR is only $10 \%$ of that of the Troms $\varnothing$ heater. In addition, SPEAR is located $\sim 2000 \mathrm{~km}$ from each of the CUTLASS radars $(1800 \mathrm{~km}$ from Hankasalmi and $2000 \mathrm{~km}$ from Pykkvibær). This is similar to the separation of the Pykkvibær radar from Tromsø (about twice the distance of the Hankasalmi-Troms $\varnothing$ path). Hence observations of Troms $\varnothing$ artificial scatter from Pykkvibær can provide an initial estimate of the levels of backscatter power that might be provided using SPEAR. As is evident from Fig. 3, the Pykkvibær radar certainly receives strong backscatter from artificial FAI over Troms $\varnothing$, however this is some $10-20 \mathrm{~dB}$ weaker than that observed by the Hankasalmi radar. This can be accounted for by the extra signal 
loss over the longer (1.5 hop) radio path. But, how sensitive is the Pykkvibær radar to irregularities generated by the Troms $\emptyset$ heater at lower powers? This question can be addressed by examination of Fig. 10, which shows the time series of backscatter power received by Pykkvibær from the centre of the heated ionospheric volume. In this case the data were recorded from 14.35 to 14.39 UT on 21 October 1999, another example of low power heating. This interval was selected since the radar data had a time resolution of 1 s which is higher than those shown in Fig. 3. The dashed sloping line overlaid on this figure indicates the power output of the heater, given by the scale on the right-hand side of the plot. Figure 10 demonstrates that the Pykkvibær radar detected artificial irregularities certainly for a heater output of $5 \%$ and also possibly at even lower powers. Since the Troms $\varnothing$ heater's experimental configuration on this date was such that maximum ERP was $199 \mathrm{MW}$, this implies that the CUTLASS radars should be sensitive to irregularities generated with heater ERPs of $10 \mathrm{MW}$ or less. The current configuration of the SPEAR high power facility enables an ERP of $\sim 28 \mathrm{MW}$ of RF radiation to be transmitted. A proposed future developmental phase would see this increased to about $68 \mathrm{MW}$.

Although the radar observations indicate that the irregularity amplitude was still not fully saturated at the maximum power of the Troms $\emptyset$ heater - currently the most powerful facility of this type - they also show that FAI can also be generated and sustained for much weaker heater powers (less than 10 MW ERP). This is therefore very promising for future experiments employing the SPEAR radar in its unique location on Svalbard.

Acknowledgements. The authors would like to thank the EISCAT Scientific Association for providing the EISCAT data and M. Rietveld for Troms $\varnothing$ heater operations throughout these experiments. Also, thanks are due to the EISCAT group at the RutherfordAppleton Laboratory for campaign assistance and for maintenance of the analysis software.

Topical Editor M. Pinnock thanks M. Kosch and another referee for their help in evaluating this paper.

\section{References}

Bailey, V. A. and Martyn, D. F.: Influence of electric waves in the ionosphere, Phil. Mag., 23, 369-386, 1934.

Bond, G. E.: The interaction of radio waves with the auroral ionosphere, Ph. D. thesis, University of Leicester, 1997.

Borisov, N., Senior, A., and Honary, F.: Stationary state and relaxation of artificial irregularities excited in ionospheric heating experiments, J. Plas. Phys., 71, 315, doi:10.1017/S002237780400296X, 2005.

Dysthe, K. B., Mjølhus, E., Pécseli, H. L., and Rypdal, K.: A thermal oscillating two-stream instability, Phys. Fluids, 26, 146-157, 1983.

Erukimov, L. M., Metelev, S. A., Mityakov, N. A., and Frolov, V. L.: Hysteresis effect in the artificial excitation of inhomogeneities in the ionospheric plasma, Radiophysics and Quantum Electronic (Engl. Trans. of Radiofizika), 21, 1738-1740, 1978.

Fialer, P. A.: Field-aligned scattering from a heated region of the ionosphere: observations at HF and VHF, Radio Sci., 9, 923940, 1974.

Grach, S. M., Karashtin, A. N., Mityakov, N. A., Rapoport, V. O., and Trakhtengerts, V. Y.: Thermal parametric instability in an inhomogeneous plasma (nonlinear theory), Sov. J. Plasma Phys. (Engl. Transl.), 4, 742-746, 1978.

Greenwald, R. A., Baker, K. B., Dudeney, J. R., Pinnock, M., Jones, T. B., Thomas, E. C., Villain, J.-P., Cerisier, J.-C., Senior, C., Hanuise, C., Hunsucker, R. D., Sofko, G., Koehler, J., Nielsen, E., Pellinen, R., Walker, D. M., Sato, N., and Yamagishi, H.: DARN/SuperDARN: a global view of the dynamics of high-latitude convection, Space Sci. Rev., 71, 761-796, 1995.

Gurevich, A. V., Zybin, K. P., and Lukyanov, A. V.: Stationary striations developed in the ionospheric modification, Phys. Rev. Lett., 75, 2622-2625, 1995.

Jones, T. B., Robinson, T., Stubbe, P., and Kopka, H.: A hysteresis effect in the generation of field-aligned irregularities by a highpower radio wave, Radio Sci., 18, 835-839, 1983.

Jones, T. B., Robinson, T. R., Stubbe, P., and Kopka, H.: EISCAT observations of the heated ionosphere, J. Atmos. Terr. Phys., 48, 1027-1035, 1986.

Milan, S. E., Yeoman, T. K., Lester, M., Thomas, E. C., and Jones, T. B.: Initial backscatter occurrence statistics from the CUTLASS HF radars, Ann. Geophys., 15, 703-718, 1997.

Minkoff, J., Kugelman, P., and Weissman, I.: Radio frequency scattering from a heated ionospheric volume, 1, VHF/UHF fieldaligned and plasma line backscatter measurements, Radio Sci., 9, 941-955, 1974.

Rietveld, M. T., Kohl, H., Kopka, H., and Stubbe, P.: Introduction to ionospheric heating at Troms $\varnothing-$ I. Experimental overview, J. Atmos. Terr. Phys., 55, 577-599, 1993.

Rishbeth, H. and Williams, P. J. S.: The EISCAT ionospheric radar: the system and its early results, Q. J. R. Astr. Soc., 26, 478-512, 1985.

Rishbeth, H. and van Eyken, A. P.: EISCAT: early history and the first ten years of operation, J. Atmos. Terr. Phys., 55, 525-542, 1993.

Robinson, T. R.: The excitation of plasma waves and irregularities in the ionosphere by means of high power radio waves, Plas. Phys. Contr. Fusion, 30, 45-56, 1988.

Robinson, T. R.: The heating of the high latitude ionosphere by high power radio waves, Phys. Rep., 179, 79-209, 1989.

Robinson, T. R., Stocker, A. J., Bond, G. E., Eglitis, P., Wright, D. M., and Jones, T. B.: O- and X-mode heating effects observed simultaneously with the CUTLASS and EISCAT radars and low power HF diagnostics at Troms $\varnothing$, Ann. Geophys., 15, 134-136, 1997.

Robinson, T. R.: Effects of multiple scatter on the propagation and absorption of electromagnetic waves in a field-aligned-striated cold magneto-plasma: implications for ionospheric modification experiments, Ann. Geophys., 20, 41-55, 2002.

Stocker, A. J., Honary, F., Robinson, T. R., Jones, T. B., Stubbe, P., and Kopka, H.: EISCAT observations of large scale electron temperature and electron density perturbations caused by high power HF radio waves, J. Atmos. Terres. Phys., 54, 1555-1572, 1992. 
Stubbe, P., Kopka, H., Lauche, H., Rietveld, M. T., Brekke, A., Holt, O., Jones, T. B., Robinson, T., Hedberg, A., Thide, B., Crochet, M., and Lotz, H. J.: Ionospheric modification experiments in northern Scandinavia, J. Atmos. Terr. Phys., 44, 1025-1041, 1982.

Stubbe, P.: Review of ionospheric modification experiments at Troms $\varnothing$, J. Atmos. Terr. Phys., 58, 349-367, 1996.

Tellegen, B. D. H.: Interaction between radio waves?, Nature, 131, 840-843, 1933.

Vaskov, V. V. and Gurevich, A. V.: Resonance instability of smallscale plasma perturbations, Sov. Phys. - JETP, 46, 487-491, 1977.
Wright, D. M., Davies, J. A., Robinson, T. R., Chapman, P. J., Yeoman, T. K., Thomas, E. C., Lester, M., Cowley, S. W. H., Stocker, A. J., Horne, R. B., and Honary, F.: Space Plasma Exploration by Active Radar (SPEAR): an overview of a future radar facility, Ann. Geophys., 18, 1248-1255, 2000.

Yeoman, T. K., Wright, D. M., Robinson, T. R., Davies, J. A., and Rietveld, M. T.: High spatial and temporal resolution observations of an impulse-driven field line resonance in radar backscatter artificially generated with the Troms $\varnothing$ heater, Ann. Geophys., 15, 634-644, 1997.

Yeoman, T. K., Wright, D. M., Stocker, A. J., and Jones, T. B.: An evaluation of range accuracy in the SuperDARN over-thehorizon radar systems, Radio Sci., 36, 801-813, 2001. 